\title{
Hypertension Subtypes among Hypertensive Patients in Ibadan
}

\author{
Abiodun M. Adeoye, ${ }^{1}$ Adewole Adebiyi, ${ }^{1}$ Bamidele O. Tayo, ${ }^{2}$ Babatunde L. Salako, ${ }^{1}$ \\ Adesola Ogunniyi, ${ }^{1}$ and Richard S. Cooper ${ }^{2}$ \\ ${ }^{1}$ Department of Medicine, University of Ibadan, Ibadan, Nigeria \\ ${ }^{2}$ Department of Public Health Sciences, Loyola University Chicago Stritch School of Medicine, Maywood, IL 60153, USA
}

Correspondence should be addressed to Abiodun M. Adeoye; adeoyemoshood@yahoo.com

Received 30 July 2014; Revised 27 September 2014; Accepted 27 September 2014; Published 19 October 2014

Academic Editor: Amgad N. Makaryus

Copyright (C) 2014 Abiodun M. Adeoye et al. This is an open access article distributed under the Creative Commons Attribution License, which permits unrestricted use, distribution, and reproduction in any medium, provided the original work is properly cited.

Background. Certain hypertension subtypes have been shown to increase the risk for cardiovascular morbidity and mortality and may be related to specific underlying genetic determinants. Inappropriate characterization of subtypes of hypertension makes efforts at elucidating the genetic contributions to the etiology of hypertension largely vapid. We report the hypertension subtypes among patients with hypertension from South-Western Nigeria. Methods. A total of 1858 subjects comprising $76 \%$ female, hypertensive, aged 18 and above were recruited into the study from two centers in Ibadan, Nigeria. Hypertension was identified using JNCVII definition and was further grouped into four subtypes: controlled hypertension $(\mathrm{CH})$, isolated systolic hypertension (ISH), isolated diastolic hypertension (IDH), and systolic-diastolic hypertension (SDH). Results. Systolic-diastolic hypertension was the most prevalent. Whereas SDH (77.6\% versus $73.5 \%)$ and IDH (4.9\% versus $4.7 \%)$ were more prevalent among females, ISH (10.1\% versus $6.2 \%)$ was higher among males $(P=0.048)$. Female subjects were more obese $(P<0.0001)$ and SDH was prevalent among the obese group. Conclusion. Gender and obesity significantly influenced the distribution of the hypertension subtypes. Characterization of hypertension by subtypes in genetic association studies could lead to identification of previously unknown genetic variants involved in the etiology of hypertension. Large-scale studies among various ethnic groups may be needed to confirm these observations.

\section{Introduction}

Cardiovascular disease is the world's number one killer. World Heart Federation statistics reveal that cardiovascular diseases account for 17.3 million deaths per year, and by 2030 this is expected to rise to 23 million. Hypertension remains a worldwide phenomenon being a major component of cardiovascular diseases with life-time cumulative incidence approaching 50\% in many populations [1]. Mass migration from rural to peri-urban and urban areas with improved industrialization and adoption of western diets and lifestyle changes have led to steady increase in incidence of hypertension in Africa $[2,3]$. In sub-Sahara alone, about 10-20 million people have hypertension with various degrees of target organ damages [4]. Based on the data available, the African Union has identified hypertension as one of its challenges after AIDS $[3,5]$.
In Nigeria, the prevalence of hypertension is on the increase among both the rural and urban settlers with resultant rising trends of sudden cardiac death [6-9]. Currently about 36 million Nigerians are estimated to have hypertension and its associated complications [9]. Despite all the advances in the study and management of hypertension, the control remains very poor. Salako et al. [10] found only $25.4 \%$ of subjects studied in a clinical setting had both systolic blood pressure (SBP) and diastolic blood pressure (DBP) controlled. Uncontrolled hypertension accounts for substantial proportion of cardiovascular deaths and morbidity resulting from stroke, heart failure, acute myocardial infarction, and kidney failure [11-13]

Prevention of hypertension and its control can markedly reduce cardiovascular morbidity and mortality; however the multifactorial aetiopathophysiologic mechanism of hypertension makes control difficult. A complex relationship 
within the environment and genetics accounts for the etiology of this disease. While the environmental factors such as obesity, diet (especially high sodium, low potassium, and excess energy intake), stress, and physical inactivity are easily elucidated, the genetic determinants of hypertension remain obscure. Heterogeneity within patient subsets and attempts to combine all hypertensives together in the search of genes has made genetic study of hypertension highly challenging and mostly difficult. It is possible that hypertension is due to multiple distinct genes that can be studied better by subdividing hypertensive subtypes and this approach may help elucidate the genetics and pathophysiology of hypertension. The search for homogeneous hypertension subtypes has in the recent years widened the scope of our understanding of monogenic Mendelian hypertension [14]. It was shown that primary hypertension with hypokalemia has different pathophysiologic mechanism than those without hypokalemia. Also Jiménez et al. [15] described an association between predominantly diastolic hypertension (PDH) subtypes and the angiotensin-converting enzyme DD polymorphism in a small population of untreated patients with $\mathrm{PDH}$. Most of the studies being undertaken to define the genetic influences have been in western societies where high levels of exposure to environmental risk factors prevail, especially obesity and excess sodium intake $[16,17]$. To broaden the perspective on the subtypes of this condition we report a case series of subjects with hypertension at the University College Hospital and Adeoyo State Hospital Ibadan, Nigeria.

\section{Materials and Methods}

2.1. Study Design and Population. This cross-sectional descriptive study was conducted at the Medical Outpatient clinics of University College Hospital and Adeoyo State Hospital Ibadan, a secondary healthcare center, Oyo State, South West Nigeria. The two hospitals serve as referral centers for primary health care centers in Ibadan. Ibadan is the capital city of Oyo State in the south-western area of Nigeria and has a population of 3.6 million, while Oyo State has 5.6 million people according to the National Population census 2007. The Yoruba ethnic group is the major tribe in Ibadan city, while other major Nigerian ethnic groups like Igbo and Hausa are fairly represented. Christianity, Islam, and traditional religions are widely practiced in Ibadan. The city has a tropical wet and dry climate with a lengthy wet season and relatively constant temperatures throughout the course of the year. There are two peaks for rainfall, June and September. The mean maximum temperature is $26.46^{\circ} \mathrm{C}$, minimum $21.42^{\circ} \mathrm{C}$, and the relative humidity is $74.55 \%$.

A total of 1858 hypertensive subjects, aged 18 years and above, of Yoruba tribe comprising 1411 females and 447 males were recruited into the study over two and half years between June 2009 and December 2011. Written informed consent was obtained from all participants. Only consenting participants of Yoruba tribe were included in the study. Subjects with fasting plasma glucose of greater than $126 \mathrm{mg} / \mathrm{dL}$ and plasma creatinine of greater than $1.5 \mathrm{mg} / \mathrm{dL}$ and those that refused consent were excluded from the study. The research protocol was approved by the joint Ethics Committee of the University College Hospital/University of Ibadan, Nigeria, and by the Institutional Review Board at Loyola University Medical Center, Maywood, IL, USA.

2.2. Data Collection. All measurements were conducted by one trained physician and two nurses between 8:00 am and 12:00 pm at Adeoyo State Hospital and $2 \mathrm{pm}$ and $6 \mathrm{pm}$ at medical outpatient, University College Hospital, Ibadan respectively. Blood pressure (BP) was measured using a standard Omron (HEM711DLX) blood pressure apparatus on the left arm after 5-minute rest using a cuff of appropriate size with the subject in the sitting position. Three BP measurements were obtained with a minimum interval of one minute and mean values were used in the analysis. Anthropometric measurements including height, weight, and waist and hip circumferences were obtained. Height was measured without shoes to the nearest centimeter using a ruler attached to the wall, while weight was measured to the nearest $0.1 \mathrm{~kg}$ on an electronic scale with the subject wearing light outdoor clothing and no shoes. Waist circumference was measured at the narrowest part of the participant's torso (or the minimum circumference between the rib cage and the iliac crest) [18] using an anthropometric measuring tape. The measurement was taken at the end of expiration. We measured waist circumference, recorded to the nearest tenth of a centimeter, 3 times and used the average of the 3 measurements.

Hypertension was defined as SBP $\geq 140 \mathrm{mmHg}$ and/or $\mathrm{DBP} \geq 90 \mathrm{mmHg}$ or being on pharmacological treatment for hypertension. Hypertension subsubtypes were defined as follows: controlled hypertension $(\mathrm{CH})$ if on antihypertensive medication, SBP $<140$ and $\mathrm{DBP}<90$; isolated systolic hypertension (ISH) if SBP $\geq 140$ and $\mathrm{DBP}<90$; isolated diastolic hypertension if SBP $<140$ and DBP $\geq 90$; systodiastolic hypertension (SDH) if SBP $\geq 140$ and DBP $\geq 90$; and predominantly diastolic hypertension $(\mathrm{PDH})$ group as subjects having a pulse pressure $(\mathrm{PP})$ to $\mathrm{DBP}$ ratio $<0.45$.

Obesity was classified based on body mass index (BMI) in $\mathrm{kg} / \mathrm{m}^{2}$ as normal $(<25$ and $>20)$, overweight $(>25$ and $<30)$, obesity ( $>30$ and $<35)$, and severe obesity $(\geq 35)$. Abdominal obesity was defined as waist circumference of greater than or equal to $102 \mathrm{~cm}$ in men and greater than or equal to $88 \mathrm{~cm}$ in women.

2.3. Statistical Analysis. Data was analyzed using the Statistical Package for Social Sciences (SPSS Inc, Chicago, IL) version 15. Results were expressed as either mean values ( \pm standard deviation) or proportions. Comparison for statistical significance was by independent Student's $t$-test for continuous variables or chi-square for categorical variables. One way analysis of variance (ANOVA) with Bonferroni's post hoc method was used to compare the demographic and BP indices among the various $\mathrm{BP}$ subtype groups. The level of significance was set at $P \leq 0.05$.

\section{Results}

A total of 1858 hypertensive subjects (mean age $49 \pm 9$ years) comprising 1411 females and 443 male participants were 
TABLE 1: Basic characteristics of the population.

\begin{tabular}{|c|c|c|c|c|}
\hline Variable & Female $(n=1411)$ & Male $(n=447)$ & Total $(n=1858)$ & $P$ value \\
\hline Age (yrs) & $48.9(8.29)$ & $47.2(10.58)$ & $48.5(8.92)$ & $<0.002^{*}$ \\
\hline Weight $(\mathrm{kg})$ & $70.7(15.20)$ & $71.2(14.15)$ & $70.9(15.66)$ & 0.521 \\
\hline Height (m) & $1.6(0.07)$ & $1.7(0.07)$ & $1.61(8.09)$ & $<0.001^{*}$ \\
\hline Arm circumference $(\mathrm{cm})$ & $29.1(4.14)$ & $27.8(3.12)$ & $28.8(4.01)$ & $<0.001^{*}$ \\
\hline Heart rate & $89.7(16.42)$ & $85.9(15.85)$ & $89.1(18.61)$ & $<0.001^{*}$ \\
\hline Systolic blood pressure (mmHg) & $161.6(25.50)$ & $161.2(24.15)$ & $161.8(26.99)$ & 0.766 \\
\hline Diastolic blood pressure $(\mathrm{mmHg})$ & $101.4(14.07)$ & $100.6(15.23)$ & $101.4(15.80)$ & 0.338 \\
\hline Body mass index $\left(\mathrm{kg} / \mathrm{m}^{2}\right)$ & $28.1(5.80)$ & $25.2(4.80)$ & $29.13(7.27)$ & $<0.001^{*}$ \\
\hline BMI groups & & & & $<0.001^{*}$ \\
\hline Normal & $376(28.5)$ & $199(49.8)$ & $575(33.4)$ & \\
\hline Overweight & 447 (33.9) & $140(35.0)$ & $587(34.1)$ & \\
\hline Obese & $320(24.2)$ & $52(13.0)$ & $372(21.6)$ & \\
\hline Severe obesity & $177(13.4)$ & $9(2.3)$ & $186(10.8)$ & \\
\hline Waist-to-height ratio & $0.708(0.16)$ & $0.712(0.14)$ & $0.709(8.10)$ & 0.635 \\
\hline Abdominal obesity & $496(35.1)$ & $42(9.4)$ & $969(51.6)$ & $<0.001^{*}$ \\
\hline
\end{tabular}

${ }^{*}$ Statistically significant.

recruited into the study. The characteristics of the study population classified by gender are as shown in Table 1 . Females were significantly older, shorter, and heavier and had greater arm circumference and increased heart rates when compared with males. Blood pressure parameters were comparable among females and males. Anthropometric measurements showed that 587 (34.1\%) were overweight, 372 (21.6\%) obese, and 186 (10.8\%) severely obese. Compared with males, female subjects were significantly more obese $(P<0.0001)$. Similarly $51.6 \%$ of the study population had abdominal obesity with female preponderance $(P<0.0001)$. Also as seen in Figure 1, there was significant effect of obesity on the distribution of hypertension subtypes. As shown in Figure 2, SDH $(77.6 \%$ versus $73.5 \%)$ and IDH (4.9\% versus $4.7 \%)$ are more prevalent among females compared with males, whereas the prevalence of ISH (10.1\% versus $6.2 \%)$ and $\mathrm{CH}$ (11.7\% versus $11.3 \%$ ) was higher among males. Table 2 showed age group and gender relations of hypertension subsubtypes. While there was significant gender effect on the frequency of blood pressure subgroup, the age group did not affect the blood pressure subtypes. The frequency of the different hypertension subtypes among the 1858 hypertensive subjects was as follows: controlled hypertension $11.4 \%$, isolated diastolic hypertension (IDH) $4.8 \%$, isolated systolic hypertension (ISH) $7.2 \%$, and systolic and diastolic hypertension (SDH) 76.6\%. Predominantly diastolic hypertension (PDH) was observed in $329(17.7 \%)$ of the entire study population, 56 (26.4\%) of CH, 72 (80\%) of IDH, and 201 (14.1\%) of SDH. We observed significant differences between hypertension subtype groups in essentially all the physiologic and anthropometric parameters (Table 3). SDH (77.6\% versus $73.5 \%)$ and IDH (4.9\% versus $4.7 \%)$ are more prevalent among females compared with males, whereas the prevalence of ISH (10.1\% versus $6.2 \%)$ and $\mathrm{CH}(11.7 \%$ versus $11.3 \%)$ was higher among males.

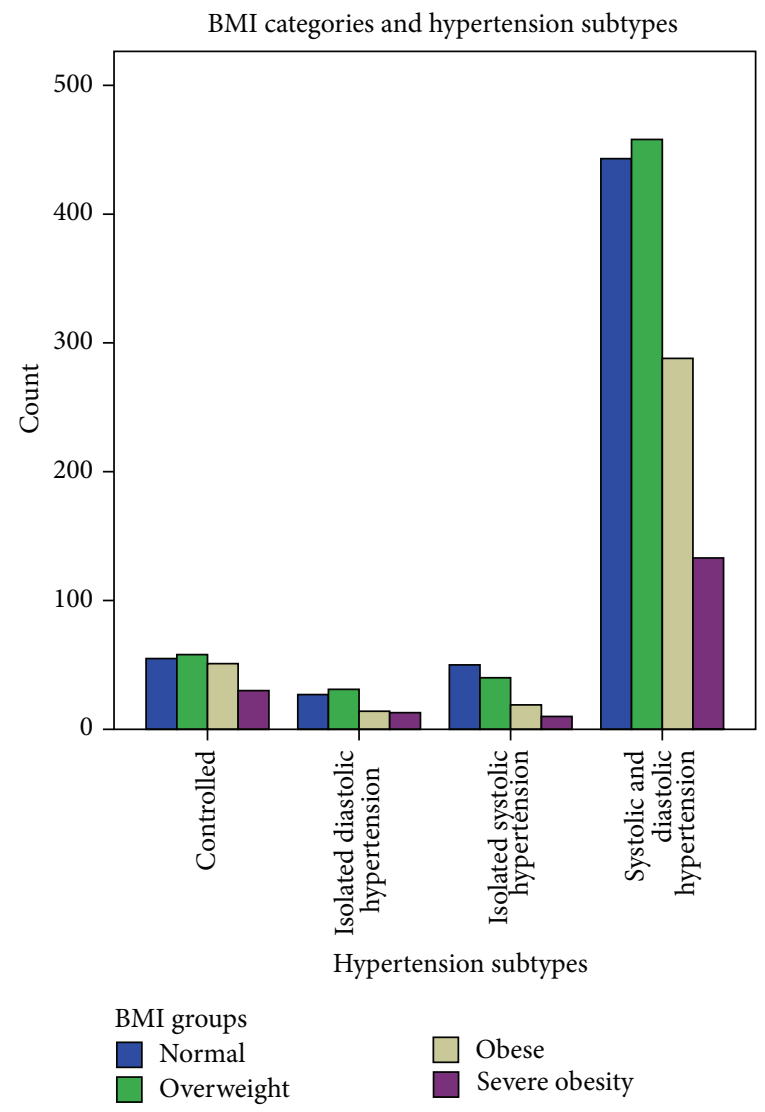

FIgURE 1: BMI categories and hypertension subtypes.

\section{Discussion}

This study shows that hypertension is a phenotype consisting of heterogeneous subtypes. The pooling of hypertension 
TABLE 2: Age group and gender relations of hypertension subtypes.

\begin{tabular}{lcccc}
\hline & $\begin{array}{c}\text { Controlled } \\
\text { hypertension } \\
(n=212)\end{array}$ & $\begin{array}{c}\text { Isolated } \\
\text { diastolic } \\
\text { hypertension }(n=90)\end{array}$ & $\begin{array}{c}\text { Isolated } \\
\text { systolic hypertension } \\
(n=133)\end{array}$ & $\begin{array}{c}\text { Systolic and } \\
\text { diastolic hypertension } \\
(n=1423)\end{array}$ \\
\hline $\begin{array}{l}\text { Gender } \\
\text { Females }\end{array}$ & $160(11.3)$ & $69(4.9)$ & $88(6.2)$ & $1096(77.6)$ \\
Males & $52(11.7)$ & $21(4.7)$ & $45(10.1)$ & $327(73.5)$ \\
Age group & $14(6.6)$ & $11(12.2)$ & $13(9.8)$ & $107(7.5)$ \\
$\quad$ Young $(\leq 39$ yrs $)$ & $185(87.3)$ & $76(84.4)$ & $107(80.5)$ & $1201(84.4)$ \\
Middle age $(40-59$ yrs $)$ & $13(6.1)$ & $3(3.3)$ & $13(9.8)$ & $115(8.1)$ \\
Elderly $(\geq 60$ yrs $)$ & & & & 0.254 \\
\hline
\end{tabular}

TABLE 3: Comparisons of demographic and BP indices in the hypertension subtypes.

\begin{tabular}{|c|c|c|c|c|c|}
\hline $\begin{array}{l}\text { Parameters } \\
\text { (means) }\end{array}$ & Controlled & $\begin{array}{c}\text { Isolated diastolic } \\
\text { hypertension }\end{array}$ & $\begin{array}{c}\text { Isolated systolic } \\
\text { hypertension }\end{array}$ & $\begin{array}{c}\text { Systolic and diastolic } \\
\text { hypertension }\end{array}$ & $P$ value \\
\hline Age & $48.80(8.52)^{\mathrm{a}}$ & $45.40(8.78)^{\mathrm{b}}$ & $50.14(9.56)^{\mathrm{a}}$ & $48.51(8.88)^{\mathrm{a}}$ & $<0.001^{*}$ \\
\hline SBP & $122.98(11.46)^{\mathrm{a}}$ & $133.15(5.80)^{b}$ & $155.33(12.56)^{\mathrm{c}}$ & $169.98(28.83)^{\mathrm{d}}$ & $<0.001^{*}$ \\
\hline DBP & $80.14(6.64)^{\mathrm{a}}$ & $97.18(9.47)^{\mathrm{b}}$ & $84.58(4.90)^{\mathrm{c}}$ & $106.41(13.85)^{\mathrm{d}}$ & $<0.001^{*}$ \\
\hline Waist & $95.02(13.53)^{c}$ & $93.41(12.23)^{\mathrm{b}, \mathrm{c}}$ & $90.08(11.84)^{\mathrm{a}}$ & $90.78(12.48)^{\mathrm{a}, \mathrm{b}}$ & $<0.001^{*}$ \\
\hline Pulse & $83.47(15.22)^{\mathrm{a}}$ & $92.40(16.09)^{\mathrm{c}}$ & $87.70(25.11)^{\mathrm{a}}$ & $89.83(18.36)^{b, c}$ & $<0.001^{*}$ \\
\hline Waist-to-height ratio & $0.74(0.16)^{\mathrm{b}}$ & $0.72(0.17)^{\mathrm{a}, \mathrm{b}}$ & $0.69(0.15)^{\mathrm{a}}$ & $0.71(0.16)^{\mathrm{a}}$ & $<0.003^{*}$ \\
\hline BMI & $28.14(6.23)^{b}$ & $27.89(5.98)^{\mathrm{b}}$ & $25.97(5.39)^{\mathrm{a}}$ & $27.46(6.24)^{b}$ & $<0.014^{*}$ \\
\hline $\mathrm{PDH}$ ratio** & $0.54(0.15)^{\mathrm{a}}$ & $0.38(0.10)^{\mathrm{b}}$ & $0.84(0.18)^{c}$ & $0.60(0.19)^{\mathrm{d}}$ & $<0.001^{*}$ \\
\hline Weight & $74.35(15.94)^{\mathrm{b}}$ & $72.06(16.85)^{\mathrm{a}, \mathrm{b}}$ & $68.63(14.63)^{\mathrm{a}}$ & $70.56(15.57)^{\mathrm{a}}$ & $<0.003^{*}$ \\
\hline Height & $162.85(7.41)^{\mathrm{b}}$ & $160.56(9.63)^{\mathrm{a}}$ & $162.63(8.02)^{b}$ & $160.50(8.03)^{\mathrm{a}}$ & $<0.001^{*}$ \\
\hline
\end{tabular}

a,b,c,d Means with the same superscript are not different at $P<0.05$.

* Statistically significant.

${ }^{* *} \mathrm{PDH}$ ratio $=$ pulse pressure/diastolic pressure.

patients without consideration for the heterogeneous nature of hypertension subtype in genetic association mapping for hypertension may have contributed to the limited success in identification of genetic variants involved in the etiology of hypertension to date.

Interestingly, studies have shown that the frequencies of various hypertension subtypes depend on the age of the cohorts studied. While some found IDH to be more prevalent among young adults others found it more prevalent among the elderly [19-23]. In the present study, subjects with IDH accounted for $4.8 \%$ of the total population and were significantly younger than those of the other groups. A report from China contradicts an early claim that linked IDH blood pressure profile with low cardiovascular risk [24]. It was demonstrated in that study that although less than ISH and $\mathrm{SDH}$, patients with IDH had higher rates of cardiovascular diseases than normotensive individuals [19, 25]. Current findings of prevalent IDH among young cohort as shown in this study require increased research interest in this group of people to prevent further hypertension associated morbidity and mortality.

Isolated systolic hypertension (ISH) is a common "pulse pressure phenotype" that has been associated with increased cardiovascular risk. In Framingham's study [26], ISH was more common among the elderly. It was shown that, among the young adults, ISH was more likely to evolve from high normal or normal blood pressure but in the elderly it most likely emanates from systo-diastolic hypertension (SDH) and IDH making two distinct types of isolated systolic hypertension. These discrepancies might suggest different genetic influence for each type of ISH. Similarly in this study, ISH was more prevalent among the older subjects and also more prevalent than IDH, but the specific categories of ISH subtypes were not studied

The gender bias in favour of females in this particular study may be explained by the nature of the community where health seeking is considered as a feminine behavior until an illness becomes severe. In this study there was a clear evidence of gender influence on the risk factors associated with hypertension. Women were significantly older, shorter, and heavier and had greater arm circumference and heart rates when compared with men. This is similar to study by Ejim et al. [8] who found hypertensive women in the Eastern Nigeria community to be heavier, taller, and older than their male counterparts. Elevated heart rate has been shown to be a risk factor for cardiovascular morbidity and mortality especially among the hypertensive [27]. Other studies also showed that elevated heart rate potentiates the risk of metabolic disturbances, diabetes, and atherosclerosis and coronary artery diseases [28]. Significantly higher heart rates among 


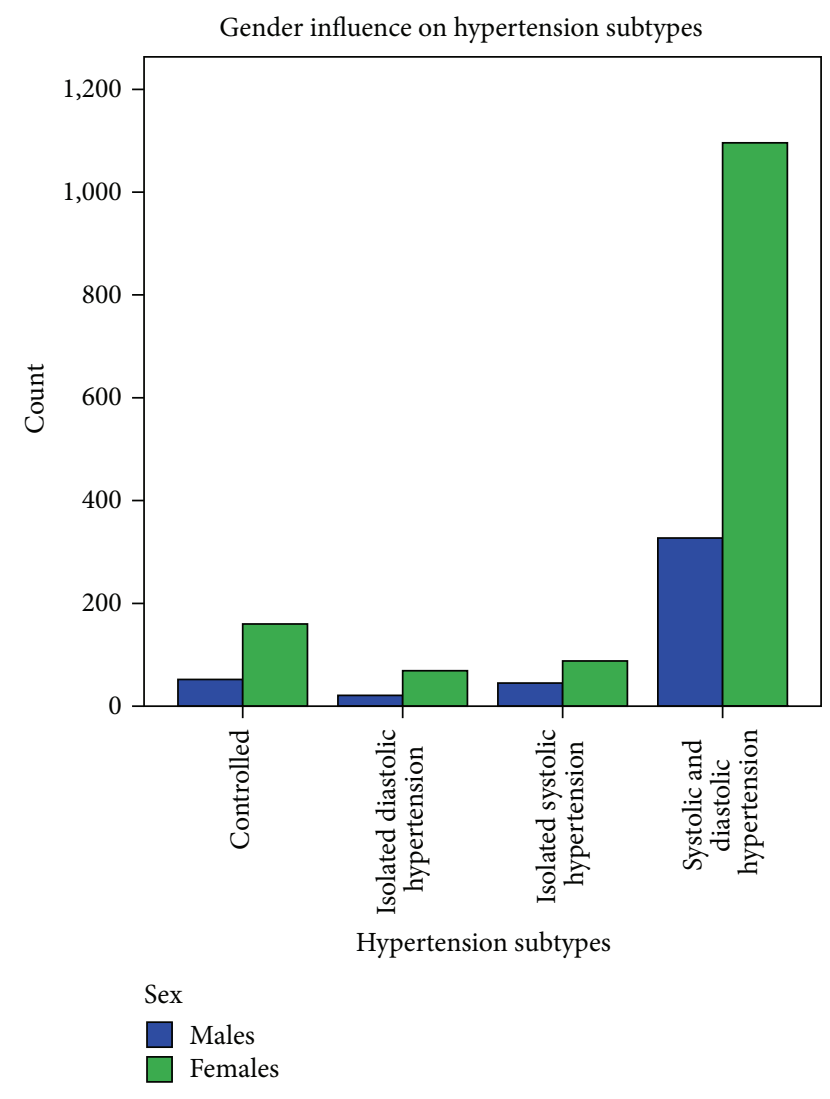

Figure 2: Gender influence on hypertension subtypes.

female as demonstrated in this study might potentiate the increased cardiovascular risk in them.

Some studies showed that patients with IDH have high prevalence of metabolic syndrome or increased body mass index $[29,30]$. In our study the IDH subtypes had increased body mass index compared to the finding of Jiménez et al. [15]. From the foregoing, the IDH subsets in our study require more attention in terms of management of hypertension and prevention of cardiovascular morbidity and mortality.

Orias et al. [31] suggested that predominantly diastolic hypertension $(\mathrm{PDH})$ describing $\mathrm{SDH}$ subsets with narrow pulse pressure tends to have similar hemodynamic patterns and are more homogenous. Also Jiménez and colleagues [15] described a link between PDH and angiotensin converting enzyme (ACE) polymorphisms in a small number of untreated hypertensives. Similar observation was reported in the Framingham cohort, which showed strong association between ACE genotype and diastolic blood pressure among men [26]. Using Blank and associates [20] definition, the prevalence of $\mathrm{PDH}$ in this study was $17.7 \%$ of general population accounting for $26.4 \%$ among $\mathrm{CH}, 80 \%$ of IDH, and $14.1 \%$ of SDH. PDH and IDH have been shown to have similar physiology which if it applies cumulatively makes the prevalence of IDH in this study almost $20 \%$ of the subject population. Some studies demonstrated the prevalence of IDH to be as high as $23 \%$. When patients with $\mathrm{PDH}$ are added to the group, IDH may account for $30 \%-40 \%$ of subjects with essential hypertension [29]. Although not conclusive it is tempting to suggest from the study that $20-25 \%$ of our studypopulation have similar haemodynamic and genetic makeup. This may suggest an association between this group and ACE genotype.

This study has shown that the heterogeneity of hypertension may also determine the degree of blood pressure control among subjects with hypertension. Gender and obesity significantly influenced the distribution of the hypertension subtypes. Prevention or control of hypertension would be better if the various subtypes are well understood. From this study, reasons for the low frequency of controlled hypertension might just not be due to nonavailability of drugs or patients poor drug adherence but also likely resulting from the varying prevalence and characteristic of hypertension subtypes as elucidated in this work.

Our study has the following limitations. The findings of this study's results may not be generalizable to the whole population because individuals attending hospital may have other comorbidities that were not taken into cognizance in this study. There is the possibility of sessional variation bias in population survey of blood pressure. However, Ibadan city has a tropical wet and dry climate with a lengthy wet season and relatively constant temperatures throughout the course of the year; we tend to believe that seasonal variation could not have significantly affected our findings in this study. Also, since the subjects were hypertensives on drug therapy, these could have introduced some misclassification into the subtype determination.

\section{Conclusion}

We have characterized the heterogeneous nature of hypertension with the predominantly Yoruba-speaking population of southwest Nigeria. As part of effort to identify genetic variants involved in the etiology of hypertension, the different hypertension subtypes may warrant individual consideration. Future research endeavors might focus on the young adults with isolated diastolic hypertension to prevent potential early cardiovascular morbidity and mortality. Larger studies in multiple populations may be needed to provide further insight into this.

\section{Conflict of Interests}

The authors declare that there is no conflict of interests regarding the publication of this paper.

\section{Acknowledgment}

This work was supported by the National Institutes of Health (NIH) grant from the NHLBI (R01HL053353).

\section{References}

[1] F. G. McMahon, "Management of essential hypertension: the new low-dose era," 1984. 
[2] N. P. Steyn, D. Labadarios, J. Nel, H. S. Kruger, and E. M. W. Maunder, "What is the nutritional status of children of obese mothers in South Africa?" Nutrition, vol. 27, no. 9, pp. 904-911, 2011.

[3] L. H. Opie and Y. K. Seedat, "Hypertension in Sub-Saharan African populations," Circulation, vol. 112, no. 23, pp. 35623568, 2005.

[4] P.-J. Touboul, R. Hernández-Hernández, S. Küçükoǧlu et al., "Carotid artery intima media thickness, plaque and framingham cardiovascular score in Asia, Africa/Middle East and Latin America: the PARC-AALA study," The International Journal of Cardiovascular Imaging, vol. 23, no. 5, pp. 557-567, 2007.

[5] Y. K. Seedat, "Hypertension in developing nations in subSaharan Africa," Journal of Human Hypertension, vol. 14, no. 1011, pp. 739-747, 2000.

[6] O. Oladapo, L. Salako, L. Sadiq, K. Soyinka, and A. Falase, "Knowledge of hypertension and other risk factors for heart disease among Yoruba rural southwestern Nigerian population," British Journal of Medicine \& Medical Research, vol. 3, no. 4, pp. 993-1003, 2013.

[7] R. Cooper, C. Rotimi, S. Ataman et al., "The prevalence of hypertension in seven populations of West African origin," The American Journal of Public Health, vol. 87, no. 2, pp. 160-168, 1997.

[8] E. C. Ejim, C. I. Okafor, A. Emehel et al., "Prevalence of cardiovascular risk factors in the middle-aged and elderly population of a nigerian rural community," Journal of Tropical Medicine, vol. 2011, Article ID 308687, 2011.

[9] I. E. Obinna and N. A. Cletus, "A meta analysis of prevalence rate of hypertension in Nigerian populations," Journal of Public Health and Epidemiology, vol. 3, no. 13, pp. 604-607, 2011.

[10] B. Salako, O. Ayodele, S. Kadiri, and A. Arije, "Assessment of blood pressure control in a Black African population," Cardiologie Tropicale, vol. 28, no. 109, pp. 3-6, 2002.

[11] W. B. Kannel, "Elevated systolic blood pressure as a cardiovascular risk factor," The American Journal of Cardiology, vol. 85, no. 2, pp. 251-255, 2000.

[12] A. Mosterd, R. B. D’Agostino, H. Silbershatz et al., "Trends in the prevalence of hypertension, antihypertensive therapy, and left ventricular hypertrophy from 1950 to 1989," The New England Journal of Medicine, vol. 340, no. 16, pp. 1221-1227, 1999.

[13] A. Falase, O. Ayeni, G. Sekoni, and O. Odia, "Heart failure in Nigerian hypertensives," African Journal of Medicine and Medical Sciences, vol. 12, no. 1, pp. 7-15, 1983.

[14] R. P. Lifton, A. G. Gharavi, and D. S. Geller, "Molecular mechanisms of human hypertension," Cell, vol. 104, no. 4, pp. 545556, 2001.

[15] P. M. Jiménez, C. Conde, A. Casanegra, C. Romero, A. H. Tabares, and M. Orías, "Association of ACE genotype and predominantly diastolic hypertension: a preliminary study," Journal of the Renin-Angiotensin-Aldosterone System, vol. 8, no. 1, pp. 42-44, 2007.

[16] D. Levy, G. B. Ehret, K. Rice et al., "Genome-wide association study of blood pressure and hypertension," Nature Genetics, vol. 41, no. 6, pp. 677-687, 2009.

[17] C. Newton-Cheh, T. Johnson, V. Gateva et al., "Genome-wide association study identifies eight loci associated with blood pressure," Nature Genetics, vol. 41, no. 6, pp. 666-676, 2009.

[18] J. C. Seidell, H. S. Kahn, D. F. Williamson, L. Lissner, and R. Valdez, "Report from a centers for disease control and prevention workshop on use of adult anthropometry for public health and primary health care," The American Journal of Clinical Nutrition, vol. 73, no. 1, pp. 123-126, 2001.

[19] S. S. Franklin, M. J. Jacobs, N. D. Wong, G. J. L'Italien, and P. Lapuerta, "Predominance of isolated systolic hypertension among middle-aged and elderly US hypertensives: analysis based on National Health and Nutrition Examination Survey (NHANES) III," Hypertension, vol. 37, no. 3, pp. 869-874, 2001.

[20] S. G. Blank, S. J. Mann, G. D. James, J. E. West, and T. G. Pickering, "Isolated elevation of diastolic blood pressure: real or artifactual?” Hypertension, vol. 26, no. 3, pp. 383-389, 1995.

[21] T. G. Pickering, "Isolated diastolic hypertension," Journal of Clinical Hypertension, vol. 5, no. 6, pp. 411-413, 2003.

[22] J. Fang, S. Madhavan, H. Cohen, and M. H. Alderman, "Isolated diastolic hypertension: a favorable finding among young and middle-aged hypertensive subjects," Hypertension, vol. 26, no. 3, pp. 377-382, 1995.

[23] W. B. Nielsen, E. Lindenstrøm, J. Vestbo, and G. B. Jensen, "Is diastolic hypertension an independent risk factor for stroke in the presence of normal systolic blood pressure in the middleaged and elderly?" American Journal of Hypertension, vol. 10, no. 6, pp. 634-639, 1997.

[24] T. N. Kelly, D. Gu, J. Chen et al., "Hypertension subtype and risk of cardiovascular disease in chinese adults," Circulation, vol. 118, no. 15, pp. 1558-1566, 2008.

[25] S. S. Franklin, "The importance of diastolic blood pressure in predicting cardiovascular risk," Journal of the American Society of Hypertension, vol. 1, no. 1, pp. 82-93, 2007.

[26] S. S. Franklin, J. R. Pio, N. D. Wong et al., "Predictors of newonset diastolic and systolic hypertension: the framingham heart study," Circulation, vol. 111, no. 9, pp. 1121-1127, 2005.

[27] S. Cook, M. Togni, M. C. Schaub, P. Wenaweser, and O. M. Hess, "High heart rate: a cardiovascular risk factor?" European Heart Journal, vol. 27, no. 20, pp. 2387-2393, 2006.

[28] M. W. Gillman, W. B. Kannel, A. Belanger, and R. B. D’Agostino, "Influence of heart rate on mortality among persons with hypertension: the framingham study," American Heart Journal, vol. 125, no. 4, pp. 1148-1154, 1993.

[29] S. S. Franklin, M. G. Barboza, J. R. Pio, and N. D. Wong, "Blood pressure categories, hypertensive subtypes, and the metabolic syndrome," Journal of Hypertension, vol. 24, no. 10, pp. 20092016, 2006.

[30] H. Wu, J. Xu, L. Zhuo et al., "Comparison of risk factors associated with hypertension subtypes by classification tree method in tongshan county of jiangsu province, China," The American Journal of Hypertension, vol. 22, no. 12, pp. 1287-1294, 2009.

[31] M. Orias, A. H. Tabares, and A. J. Peixoto, "Hypothesis: it is time to reconsider phenotypes in hypertension," The Journal of Clinical Hypertension, vol. 12, no. 5, pp. 350-356, 2010. 


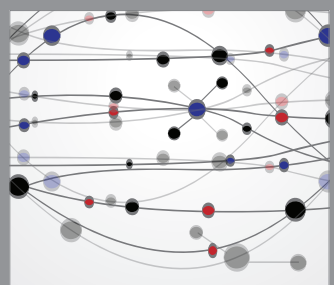

The Scientific World Journal
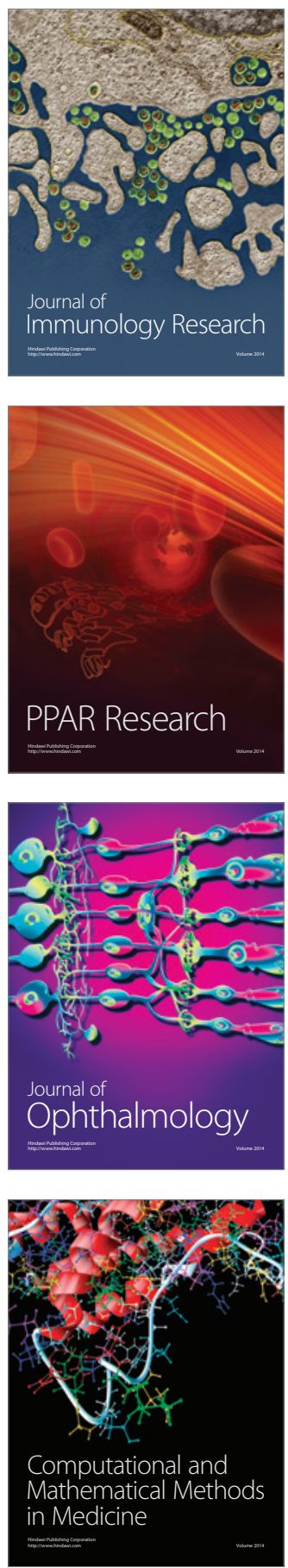

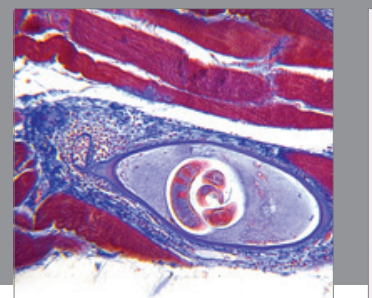

Gastroenterology

Research and Practice
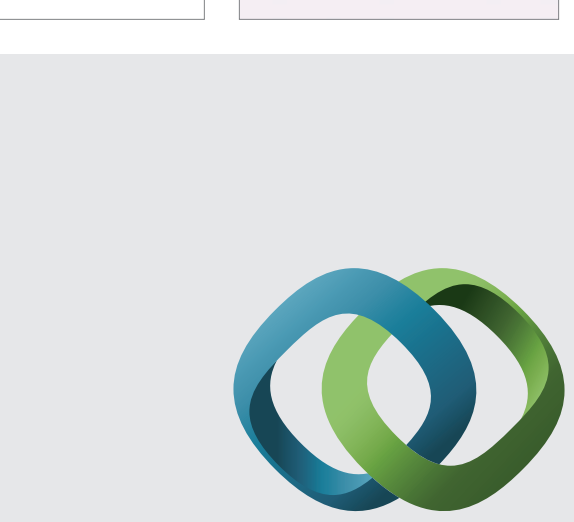

\section{Hindawi}

Submit your manuscripts at

http://www.hindawi.com
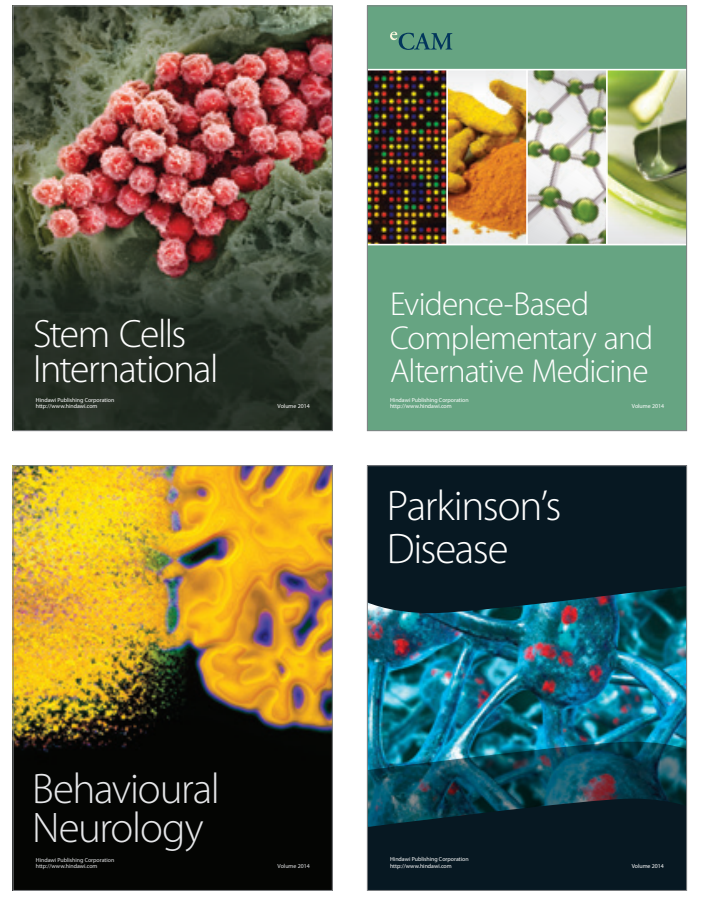
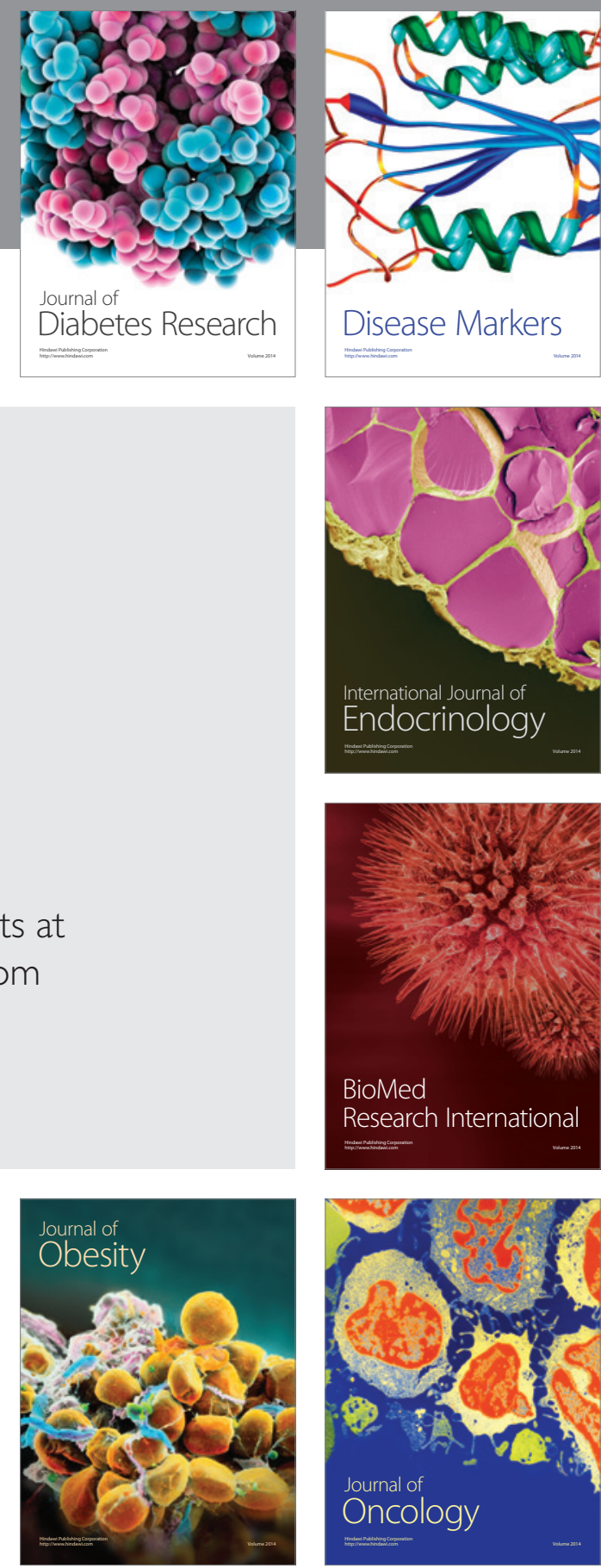

Disease Markers
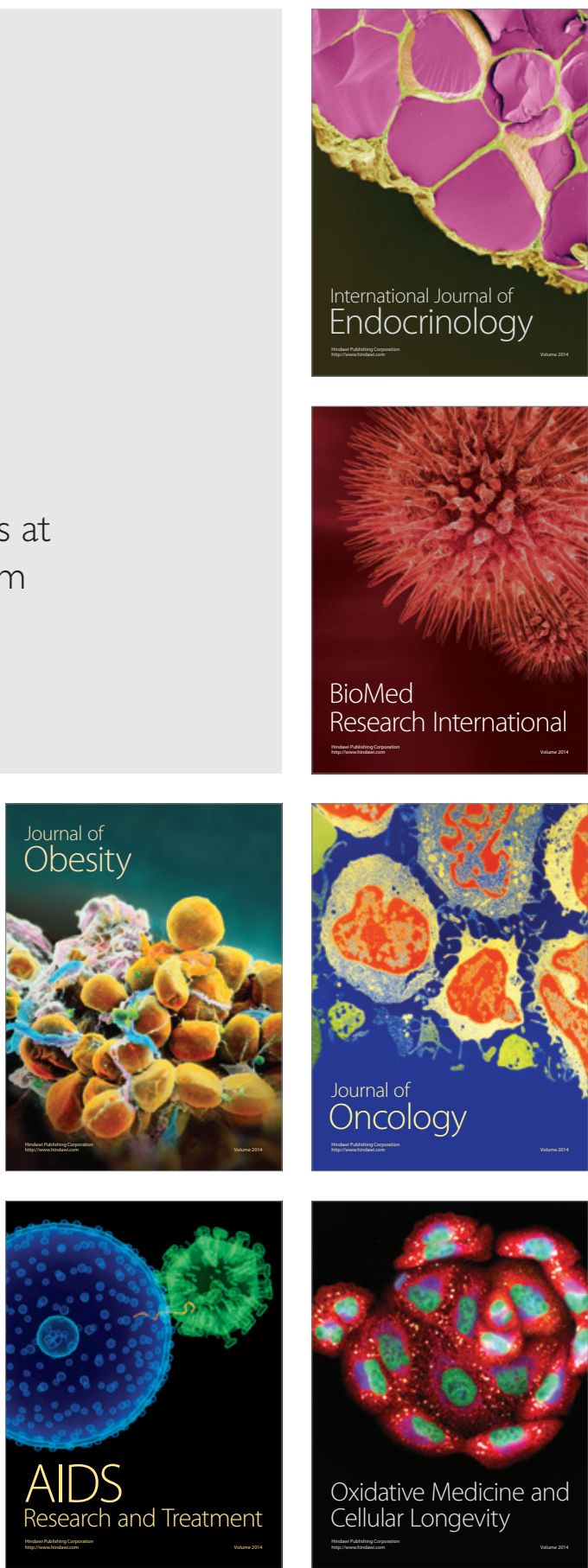